\title{
Better insight into the nano-mechanical properties of flax fibre cell walls Olivier Arnould ${ }^{\mathrm{a}, \mathrm{b}, *}$, , David Siniscalco ${ }^{\mathrm{a}}$, Alain Bourmaud ${ }^{\mathrm{a}}$, Antoine Le Duigou ${ }^{\mathrm{a}}$, Christophe Baley ${ }^{\mathrm{a}}$ \\ a IRDL, Université Européenne de Bretagne, CNRS, FRE 3744, Lorient, France \\ ${ }^{\mathrm{b}}$ LMGC, Université de Montpellier, CNRS, UMR 5508, Montpellier, France
}

Keywords:

AFM (Atomic Force Microscopy)

PF-QNM (Peak-Force Quantitative

Nano-Mechanical property mapping)

Nanoindentation

Flax fibre

Aramid fibre
Peak-Force Quantitative Nano-Mechanical property mapping (PF-QNM) was applied to explore the nanomechanical properties of flax fibre cell walls in cross-section. After validation of the ability of PF-QNM to determine stiffness gradients in aramid fibres, measurements were performed on developing flax bast fibres. The presence of two layers with different indentation moduli implies their progressive develop-ment during thickening of the secondary cell wall. Finally, measurements were carried out on technical flax fibre cell wall; but, in this case, no significant stiffness gradient could be identified in the secondary $\mathrm{S}_{2}$ layer.

\section{Introduction}

The industrial interest in using plant bast fibres for composite reinforcement is increasing due to their low environmental impact, recycling ability and biobased sourcing. In addition, owing to their low density and very interesting specific mechanical properties, bast fibres are attractive for transport applications. Although tensile properties of elementary fibres are well described in the literature; more mechanical information is required at the cell walls scale to improve our understanding of the relationship between their ultrastructure and properties.

Indeed, an elementary flax fibre is itself assumed to be a composite because of its specific ultrastructure made up of several cell walls and layers. The $S_{2}$ layer of the secondary cell wall, which mainly controls the longitudinal mechanical properties, is composed of $\approx 70 \%$ oriented cellulose microfibrils embedded in an amorphous polysaccharide matrix containing hemicelluloses and pectins (Mikshina et al., 2013). During plant development, the secondary cell wall of the outer bast fibre bundles firstly becomes

* Corresponding author at: IRDL, Université Européenne de Bretagne, CNRS, FRE 3744, Lorient, France.

E-mail address: olivier.arnould@umontpellier.fr (O. Arnould). thickened, while complete filling takes around two months. Consequently, during fibre development, the degree of maturity may differ between the outer and inner fibres (Gorshkova et al., 2003). Fibres can thus have a skin-core like ultrastructure, e.g., the socalled $\mathrm{G}$ and $\mathrm{Gn}$ sub-layers in the developing secondary cell wall (Mikshina et al., 2013). The associated spatial cell-wall stiffening has not been measured yet and is an interesting parameter to better understand the evolution of flax stem stability during growth and more especially in the case of lodging. Even in mature fibres, it is possible that changes in growth, maturation, retting or scutching conditions could induce mechanical gradients within the cell wall. For composite reinforcement application, the existence of a mechanical skin-core effect is a key parameter linked to the fibre peeling and cohesion with the matrix. In case of flax fibre, the peeling phenomenon is not always observed (Le Duigou et al., 2012), suggesting a relative homogeneity into fibre structure.

Nanoindentation is a widespread method for mechanical characterization at the micrometre scale and is now well developed for studying plant fibres at the secondary cell wall scale (Bourmaud and Baley, 2012; Eder et al., 2013), but is less well suited for studying gradients, due to the minimum indent size and required distance between indents. However, new tools based on atomic force microscopy (AFM) are available to investigate mechanical properties at the sub-micrometre scale, even in plant cell walls 
(Arnould and Arinero, 2015). The aim of the present study is to use PeakForce Quantitative Nano-Mechanical property mapping (PFQNM) as a tool to reveal potential mechanical gradients in the cell wall layers of flax fibres, using nanoindentation as a reference. First, to validate the method and explore the possibility of imaging an existing stiffness gradient, PF-QNM is used on aramid fibres, which are well known to possess a skin-core microstructure (Mc Allister et al., 2012; Wollbrett-Blitz et al., 2016) that induces a peeling effect which causes a longitudinal and transversal propagation of crack, in the skin and core layer, respectively (Morgan et al., 1983). Then, the methodology is transferred to flax fibres; modulus mapping is performed at the nanoscale both on developing and mature flax fibres.

\section{Materials and methods}

\subsection{Fibres}

The aramid fibres used in this study were K48 grade Kevlar ${ }^{\circledR}$ from DuPont ${ }^{\mathrm{TM}}$. Flax plants (Eden variety, 2016) were cultivated in Lorient (Brittany, France) with a seeding density of 1,800 plants $/ \mathrm{m}^{2}$, which corresponds to the conventional density for flax culture. Sowing was performed at the end of March. A first batch of stems was pulled 60 days after sowing, during the cell-wall thickening phase. Green stems were cut at mid height and placed directly in $50 \%$ deionised water $/ 50 \%$ ethanol solution. Mature flax fibres were obtained when the cumulative temperature exposure was sufficiently high.
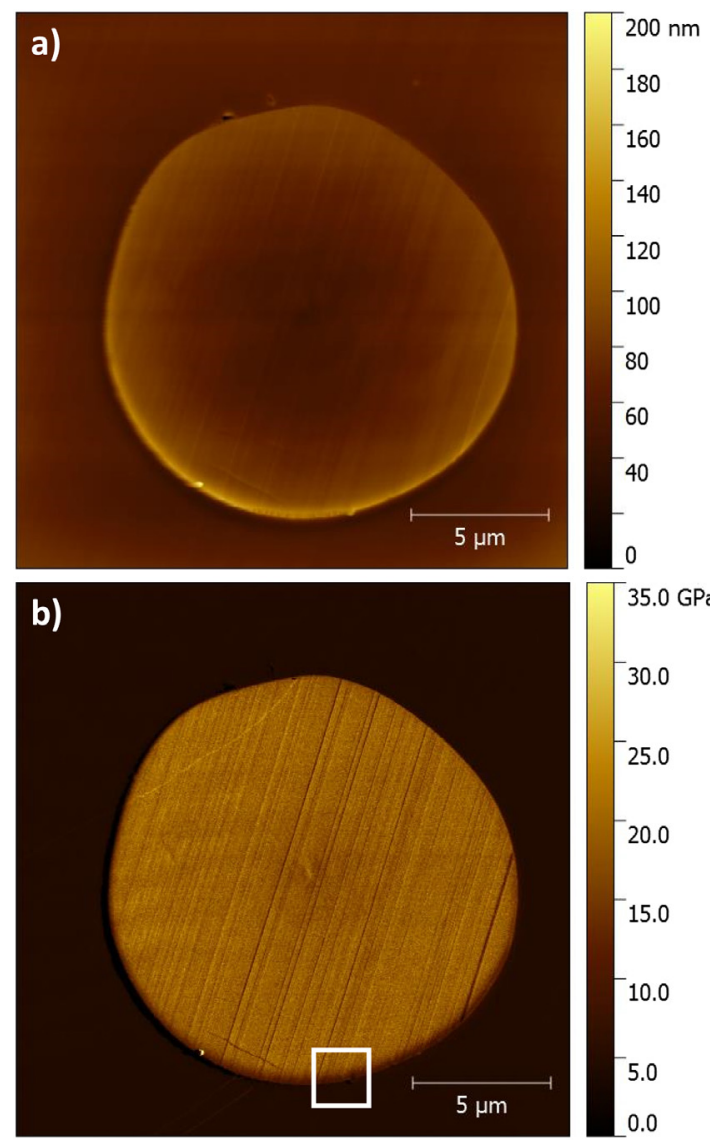

\subsection{Sample preparation}

Green stems and mature flax fibres samples were dehydrated with a concentration series of ethanol/deionised water $(50 \%, 75 \%$, $90 \%$ and $100 \%$ ) and then embedded in a mixture containing increasing ratios of LR White acrylic resin/ethanol (25\%, 50\%, 75\% and $100 \%$ ), waiting for few hours at each embedding step, in order to maintain the fibre and the cell-wall structure during surface preparation. Final resin polymerization took place in an oven $\left(60^{\circ} \mathrm{C}\right.$, overnight). Aramid fibres were placed directly in an epoxy resin (Struers Epofix) that polymerizes at ambient temperature for $24 \mathrm{~h}$. One stem sample and one sample containing several tens of mature flax fibres and another one containing several tens of aramid fibres were prepared. They were then machined, to reduce their crosssection, and an ultramicrotome (Leica Ultracut R) is then used with diamond knives (Diatome Histo and Ultra AFM) to cut a series of very thin sections (about $50 \mathrm{~nm}$ thick in the last steps) at low cutting speed $(\approx 1 \mathrm{~mm} / \mathrm{s})$.

\subsection{Nanoindentation}

A commercial nanoindentation system Nanoindenteur XP (MTS Nano Instruments) was used at room temperature, equipped with a three-side pyramid indenter (Berkovich). No nanoindentation measurements were done on developing flax bast fibres in the plant stem, as their cell-wall is usually too thin. For the mature flax fibres sample, 15 fibres were measured with around 5 acceptable indentation locations within each fibre. For the aramid fibres sample, 10 different fibres were measured with 1 indentation location close to the centre of each fibre. In all cases, a maximum indentation depth

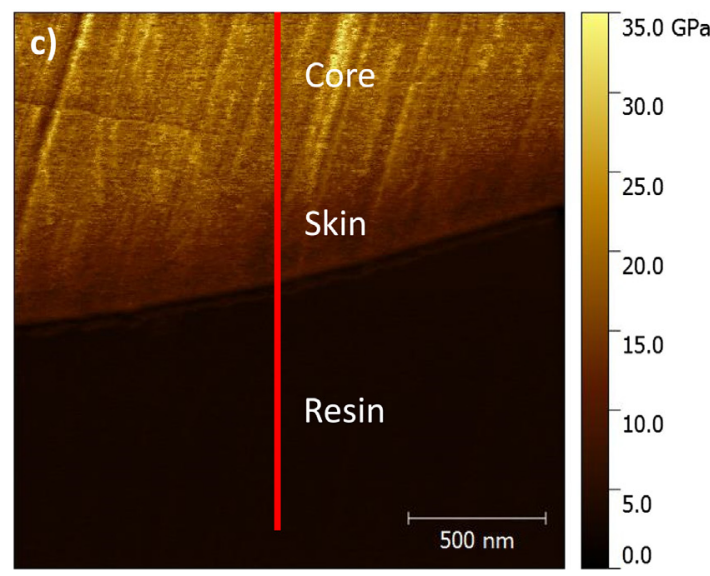

d)

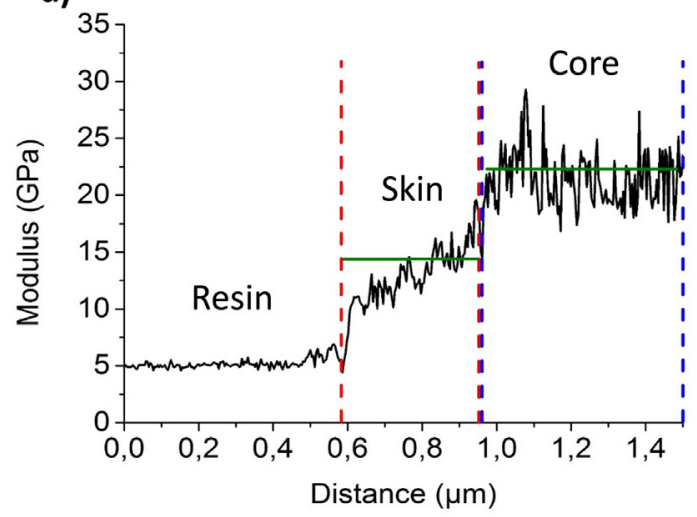

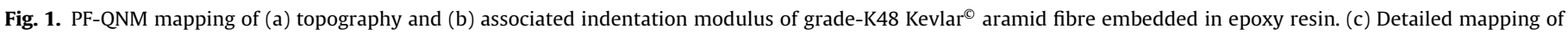
indentation modulus in the area outlined by the box in (b) and (d) variation of the contact modulus along the profile drawn in (c). 
of $150 \mathrm{~nm}$ was used with a loading rate of $0.05 \mathrm{~s}^{-1}$ (i.e., $1 \mu \mathrm{N} / \mathrm{s}$ ), followed by a holding segment at maximum load for $20 \mathrm{~s}$ before unloading at a rate of $10 \mu \mathrm{N} / \mathrm{s}$, after which a final holding segment was carried out for thermal drift assessment and correction. The indentation modulus was obtained using the unloading curve and the classical approach of Oliver and Pharr (2004). For all samples, the indentation modulus was measured in the embedding resin too and serves as a control for matching with AFM measurements.

\subsection{AFM peak force QNM}

Mechanical characterization was performed with a Multimode AFM instrument (Bruker Corporation, USA) using PF-QNM imaging mode and a RTESPA-525 (Bruker) probe with a spring constant of $139 \mathrm{~N} / \mathrm{m}$. The probe was calibrated using the so-called Sader method (http://www.ampc.ms.unimelb.edu.au/afm) with a Scanning Electron Microscope (Jeol JSM 6460LV) for measurements of the cantilever length and width. The tip radius, $32 \mathrm{~nm}$, was tuned during measurement on a Highly Oriented Pyrolytic Graphite (HOPG) standard from Bruker, providing an indentation modulus of around $18 \mathrm{GPa}$. The applied maximum load was set at $200 \mathrm{nN}$ for all the measurements. As the measurements are longer and more subjected to artefact and drift with this technique, a reduced number of fibres have been measured compared to nanoindentation (i.e., 5 developing flax bast fibres, 5 mature flax fibres and 5 aramid fibres).

\section{Results and discussion}

To demonstrate the sensitivity of PF-QNM for detecting material gradients, we analysed a model sample (i.e., Kevlar ${ }^{\mathbb{B}}$ fibre) known for its possible skin-core structure (Mc Allister et al., 2012; Wollbrett-Blitz et al., 2016). Fig. 1a and b show the surface topography of the cross-section of such a fibre with its indentation modulus map. A detailed view of the indentation modulus near the edge of the fibre is shown on Fig. 1c, together with the variation of the indentation modulus along a profile shown in red on Fig. 1d. We can observe three distinct and successive indentation (or contact) modulus domains: firstly, the domain ranging from 0 to $0.6 \mu \mathrm{m}$ corresponds to the modulus of the resin of around $4.5 \pm 0.2 \mathrm{GPa}$ (confirmed by nanoindentation). Then, two domains in the aramid fibre between 0.6 and $1.0 \mu \mathrm{m}$ and from 1.0 to $1.5 \mu \mathrm{m}$, with average moduli of $16.0 \pm 2.9 \mathrm{GPa}$ and $21.0 \pm 2.9 \mathrm{GPa}$, respectively. The latter value is confirmed by nanoindentation $(22.8 \pm 1.7 \mathrm{GPa})$. These results are in agreement with other literature data. For example, Wollbrett-Blitz et al. (2016) studied the elastic properties of K29-grade Kevlar ${ }^{\circledR}$ fibres. Based on their data, we can apply an
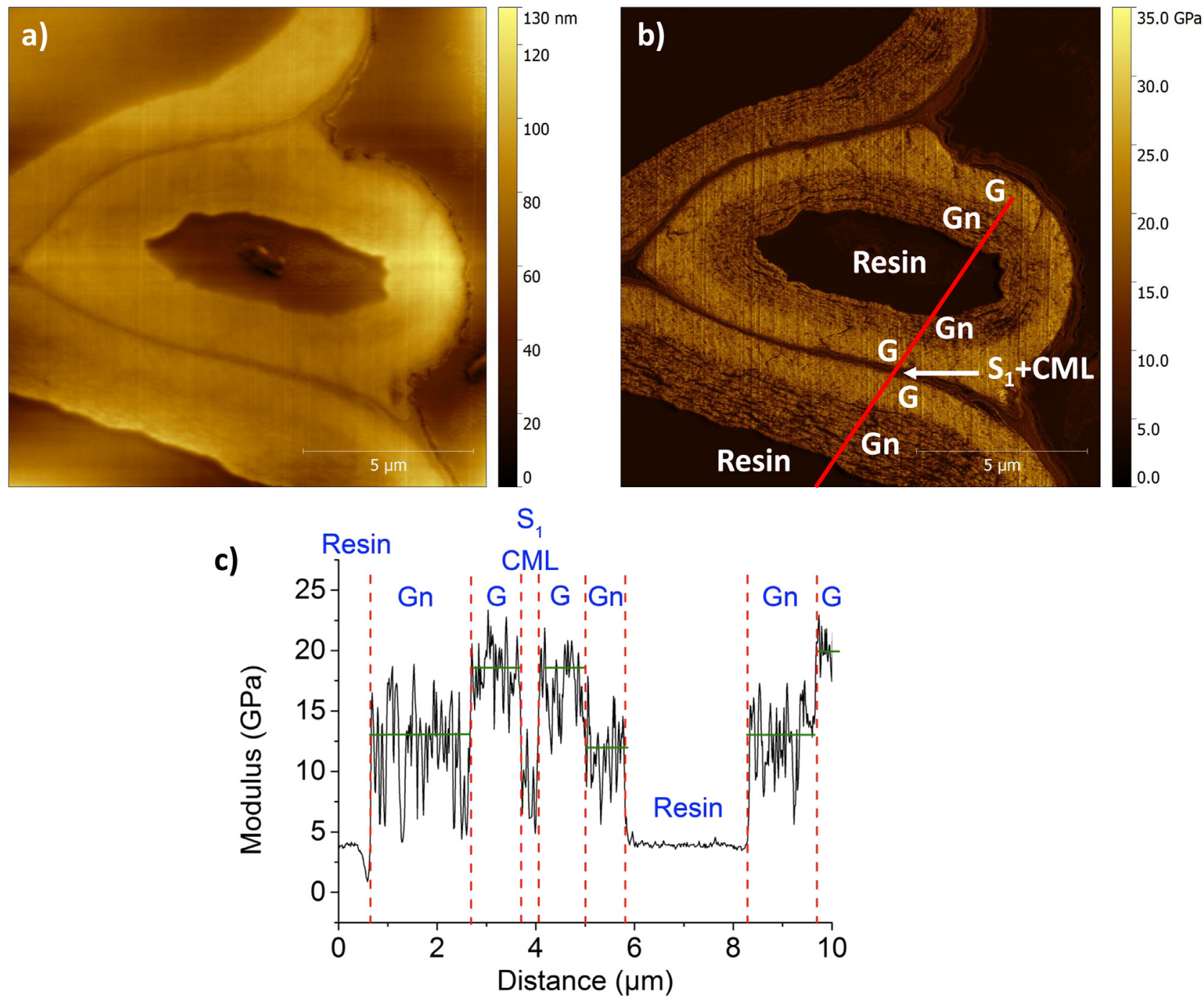

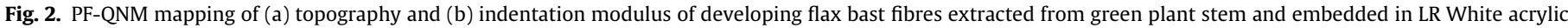

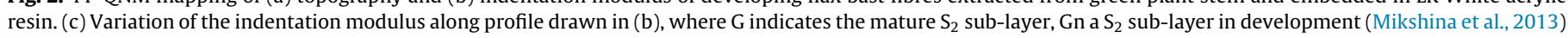
and CML the compound middle lamella. 

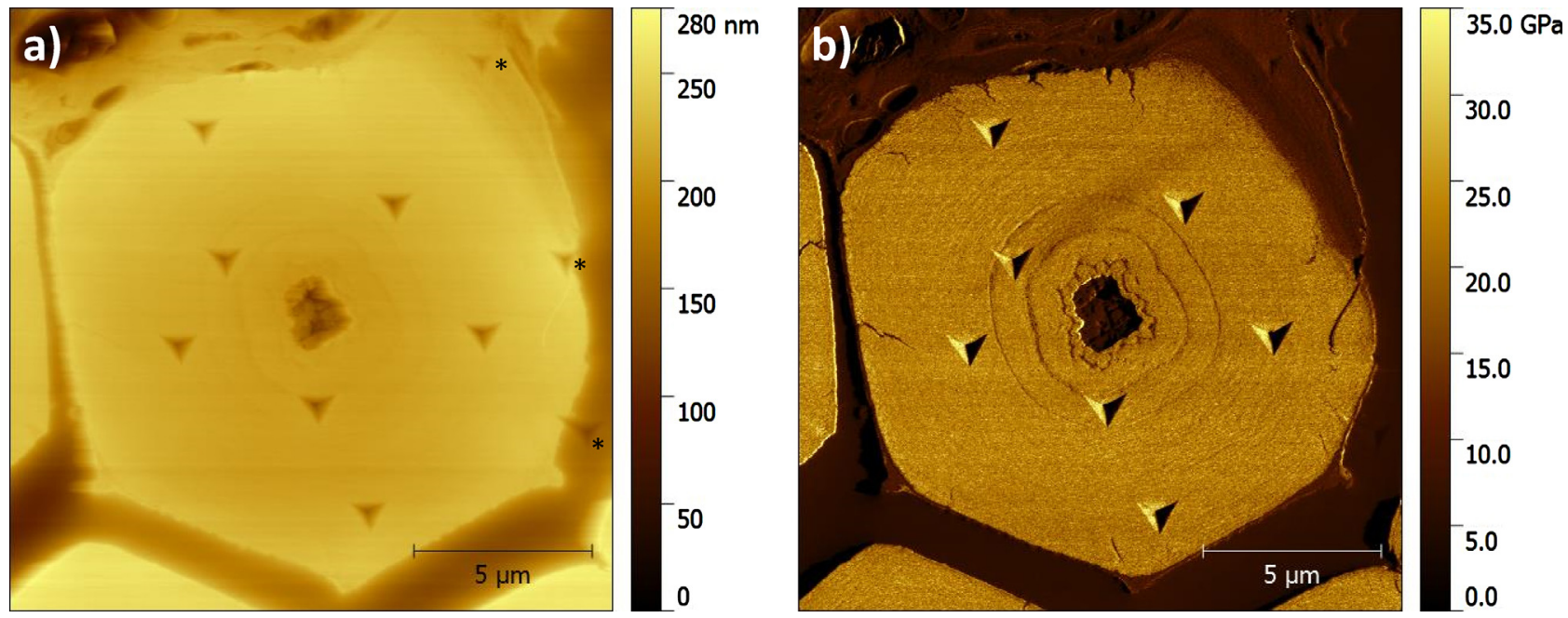

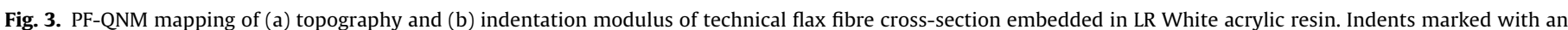
asterisk $\left({ }^{*}\right)$ are excluded from the analysis.

anisotropic indentation model (Delafargue and Ulm, 2004) to calculate a core indentation modulus of $\approx 21 \mathrm{GPa}$ and a skin indentation modulus of $\approx 17 \mathrm{GPa}$. In their study, Wollbrett-Blitz et al. (2016) estimate a skin thickness of $1 \mu \mathrm{m}$ compared to the value of around $0.4 \mu \mathrm{m}$ obtained here. Thus, PF-QNM is proved to be able to be sensitive to mechanical gradients within a thin area, as other AFM techniques in such a fibre (Mc Allister et al., 2012) or in wood fibres (Arnould and Arinero, 2015).

In the present approach, we carry out indentation modulus mapping on developing flax bast fibres derived from plant stems pulled 60 days after sowing (Fig. 2). On the indentation modulus map, we can clearly observe the presence of different domains, contrary to the topography images, especially in the $S_{2}$ layer of the fibres. For the fibre in the centre and immediately below, the $S_{2}$ layer is divided into two domains. The $\mathrm{G}$ domain is significantly stiffer (i.e., indentation modulus of $18.0 \pm 2.9 \mathrm{GPa}$ ) than the $\mathrm{Gn}$ domain (i.e., indentation modulus of $13.0 \pm 3.8 \mathrm{GPa}$ ). The $\mathrm{S}_{2}$ layer of the fibre in the upper-left corner is thinner and comprises a single Gn domain with low indentation modulus; this fibre is probably less developed than the other two ones. These sub-layers correspond to the thickening process involving the so-called G/Gn layers as described by Mikshina et al. (2013). The indentation modulus in the $G$ sub-layer is in agreement with values obtained by other AFM techniques for similar layers in wood cell walls (Arnould and Arinero, 2015). Note that the indentation modulus of the $S_{1}$ compound middle lamella $(\mathrm{CML})$ is around $7 \mathrm{GPa}$, in agreement with the nanoindentation results for wood (Wimmer and Lucas, 1997).

Finally, PF-QNM and nanoindentation experiments were combined to conduct experiments on mature flax fibre. In a first step, the flax fibre is analysed by nanoindentation, using ten measurements at different locations in the fibre. Fig. 3a shows a flax fibre with topography imaging showing residual indents. Three of the indents in this fibre, marked with an asterisk $\left({ }^{*}\right)$ in Fig. 3a, are excluded from the analysis since they are located close to a border or in the embedding resin between two fibres. For the other indents, the indentation modulus is $20.4 \pm 1.1 \mathrm{GPa}$, with no significant difference between each indent. This average modulus is well correlated with previous results obtained by nanoindentation measurements on another technical flax fibre variety (Bourmaud and Baley, 2012). The PF-QNM values are very close to those obtained with nanoindentation (Fig. 3b), yielding an average modulus of $21.3 \pm 2.2 \mathrm{GPa}$ in the whole cross-section. Contrary to the results obtained on aramid or developing flax bast fibres, PF-QNM measurements don't evidence any gradients in the technical flax fibre even if concentric sub-layers are observed within the $S_{2}$ layer, especially on the indentation modulus map (Fig. 3b). These results are compatible with the mapping performed by nanoindentation (Bourmaud and Baley, 2012), where border effects are observed (Jakes et al., 2009), and the thickening process of flax bast fibres in the plant (Mikshina et al., 2013).

\section{Conclusion}

Peak-Force QNM mapping is used in combination with nanoindentation on aramid and flax fibres, revealing the potential of this method for nanomechanical analysis, especially in the case of mechanical gradients at the submicrometre scale. In the case of cross-sections of grade-K48 $\mathrm{Kevlar}^{\circledR}$ fibres, this imaging method allows us to measure a skin-core effect with indentation moduli of $16.0 \pm 2.9 \mathrm{GPa}$ and $21.0 \pm 2.9 \mathrm{GPa}$, respectively, and a skin thickness of $\approx 0.4 \mu \mathrm{m}$. Interestingly, this method highlights the presence of two distinct layers in the $S_{2}$ wall of developing flax fibres with two distinct indentation moduli: $13.0 \pm 3.8 \mathrm{GPa}$ for the newly deposited Gn layer and $18.0 \pm 2.9 \mathrm{GPa}$ for the mature G layer (Mikshina et al., 2013). This innovative result contributes to a better understanding of flax fibre growth in the plant and of the evolution of the stem stability. Finally, PF-QNM combined with nanoindentation does not provide any evidence for any stiffness gradients within the $S_{2}$ layer of technical flax fibres cross-section that appears homogeneous, showing an indentation modulus of $20.4 \pm 1.1 \mathrm{GPa}$ with nanoindentation and $21.3 \pm 2.2 \mathrm{GPa}$ with PF-QNM. This homogeneity is in favour of both a better interface cohesion within a composite and limitation of peeling in case of mechanical stress.

\section{Acknowledgements}

The authors thank Helmut Gneagi (Diatome, Switzerland) and Françoise Laurans (INRA Orleans, France) for their help in sample preparation and Mickael Febrve (Brucker, France) for fruitful discussions. They are also grateful to Fiabilin, Oseo, Region Bretagne, "StressInTrees" (ANR-12-BS09-0004 funded by the French National Research Agency ANR) and CNRS for funding this work. Dr M.S.N. Carpenter post-edited the English style and grammar. 


\section{References}

Arnould, O., Arinero, R., 2015. Towards a better understanding of wood cell wall characterisation with contact resonance atomic force microscopy. Compos. Part A-Appl. Sci. 74, 69-76.

Bourmaud, A., Baley, C., 2012. Nanoindentation contribution to mechanical characterization of vegetal fibers. Compos. Part B-Eng. 43, 2861-2866.

Delafargue, A., Ulm, F.J., 2004. Explicit approximations of the indentation modulus of elastically orthotropic solids for conical indenters. Int. J. Solids Struct. 41, 7351-7360.

Eder, M., Arnould, O., Dunlop, J.W.C., Hornatowska, J., Salmén, L., 2013. Experimental micromechanical characterisation of wood cell walls. Wood Sci. Technol. 47, 163-182.

Gorshkova, T.A., Sal'nikov, V.V., Chemikosova, S.B., Ageeva, M.V., Pavlencheva, N.V., van Dam, J.E.G., 2003. The snap point: a transition point in Linum usitatissimum bast fiber development. Ind. Crop. Prod. 18, 213-221.

Jakes, J.E., Frihart, C.R., Beecher, J.F., Moon, R.J., Resto, P.J., Melgarejo, Z.H., Suarez, O.M., Baumgart, H., Elmustafa, A.A., Stone, D.S., 2009. Nanoindentation near the edges. J. Mater. Res. 24 (3), 1016-1031.

Le Duigou, A., Bourmaud, A., Balnois, E., Davies, P., Baley, C., 2012. Improving the interfacial properties between flax fibres and PLLA by a water fibre treatment and drying cycle. Ind. Crops Prod. 39, 31-39.
Mc Allister, Q.P., Gillespie, J.W., Van Landingham, M.R., 2012. Evaluation of the three-dimensional properties of Kevlar across length scales. J. Mater. Res., 14, http://dx.doi.org/10.1557/jmr.2012.80.

Mikshina, P.V., Chernova, T.E., Chemikosova, S.B., Ibragimova, N.N., Mokshina, N.Y., Gorshkova, T.A., 2013. Cellulosic fibers: role of matrix polysaccharides in structure and function. In: Van de Ven, T., Godbout, L. (Eds.), Cellulose Fundamental Aspects. InTech, pp. 91-112, http://dx.doi.org/10.5772/ 519412013.

Morgan, R.J., Pruneda, C.O., Steele, S.W., 1983. The relationship between the physical structure and the microscopic deformation and failure processes of poly(para-phenylene terephthalamide) fibers. J. Polym. Sci. Pol. Phys. 21 (9), 1757-1783.

Oliver, W.C., Pharr, G.M., 2004. Measurement of hardness and elastic modulus by instrumented indentation: advances in understanding and refinements to methodology. J. Mater. Res. 19 (1), 3-20.

Wimmer, R., Lucas, B.N., 1997. Comparing mechanical properties of secondary wall and cell corner middle lamella in spruce wood. IAWA J. 18 (1), 77-88.

Wollbrett-Blitz, J., Joannès, S., Bruant, R., Le Clerc, C., De La Osa, M.R., Bunsell, A., Marcellan, A., 2016. Multiaxial mechanical behavior of aramid fibers and identification of skin/core structure from single fiber transverse compression testing. J. Polym. Sci. Pol. Phys. 54, 374-384. 